culture could have evolved into the other without some such explanation as Prof. Dreyer proposes. But the ultimate origin of the flake-tool folk, whether one is considering those in northern latitudes or their cousins in South Africa, still remains a mystery.

\section{Synthesis of a Pituitary Hormone}

THE synthesis of oxytocin, a principal hormone of the posterior pituitary, has been announced by Prof. V. du Vigneaud, professor of biochemistry, Cornell University Medical College, and his colleagues, C. Ressler, J. M. Swan, C. W. Roberts, P. G. Katsoyannis and S. Gordon (J.Amer. Chem. Soc., 75, $4879 ;$ 1953). Oxytocin causes contractions of the uterus, and is also concerned with the 'let-down' of milk from the mammary gland. Previous work had shown that natural oxytocin on hydrolysis yields leucine, isoleucine, tyrosine, proline, glutamic acid, aspartic acid, glycine and cystine, and three molecules of ammonia. Based on these results, a synthetic product was obtained by a method described and had the biological properties of natural oxytocin. The authors remark that, if the identity of the synthetic material with oxytocin is confirmed, this will be the first synthesis of a polypeptide hormone.

\section{Japanese Journal of Tuberculosis}

MUCH activity is evident in Japan in the field of tuberculosis, and in no less than six universities there are institutes devoted to research in this disease, or in which such study figures prominently. These institutes have now joined in sponsoring a quarterly journal, the Japanese Journal of Tuberculosis (pp. 98 ; November 1953 ; from the Institute of Infectious Diseases, Shiba-Shirokane-Daimachi, Minato-Ku, Tokyo), under the editorship of Y. Takeda and with a representative editorial board. The first number presents mainly laboratory studies, but also some articles on clinical and epidemiological aspects. It is well produced and is in English. This lusty newcomer to national specialist literature invites comparison with the several British tuberculosis journals, which are showing little success in attracting scientific contributions-particularly those of a laboratory nature-away from their very scattered distribution in other publications.

\section{Photoelectric Scanners for use in Paper Electro- phoresis}

THERE are numerous descriptions in the literature of instruments for measuring the intensity of the dyed serum protein bands after electrophoresis on paper, which utilize a photoelectric cell for measuring the light transmitted or reflected from a suitable source. By plotting extinctions at given distances along the paper strips, a graph is obtained which provides a quantitative evaluation of the proteins present. Such instruments are now produced commercially. The firm of Evans Electroselenium, Ltd. (Harlow, Essex), provides, in addition to the scanning apparatus, a power unit and specially designed bath for carrying out the initial protein separation. As the scanning apparatus employs transmitted light, the dyed paper strip requires to be wetted with a suitable liquid to render it translucent. A frame carries the translucent strip between two glass plates and has a platform for holding a sheet of graph paper. The whole is moved across the light source, and extinctions read off from a microammeter and plotted on the graph paper. Joyce, Loebl and Co.,
Ltd. (Vine Lane, Newcastle upón Tyne 1), produces a somewhat more elaborate scanning apparatus (Model 2.SR), which incorporates a double-beam amplifier principle and measures reflected light, obviating the need for rendering the paper translucent. It also has a framework for moving the paper across the light source and a platform for holding graph paper; but instead of reading off the extinctions, their values are directly plotted on the graph paper by a pen attached to a slider which is adjusted until the milliammeter reads zero. A feature of both instruments is that readings may be carried out quickly and easily. They are thus suitable for routine clinical investigations. The instruments are also adaptable for measuring the intensity of coloured spots on paper chromatograms.

\section{Determination of the Resolving Power of Photo- graphic Lenses}

Circular 533 of the National Bureau of Standards, Washington, D.C., entitled "Method for Determining the Resolving Power of Photographic Lenses" (pp. iv $+27+2$ charts. Washington, D.C.: Government Printing Office, 1953; 1 dollar), replaces Circular 428 (1941), and provides the photographer with two sets of improved charts by which the resolving power of a photographic lens may be numerically measured with respect to a definite scale of values. It gives a detailed description of the procedure and technique to be followed in order that comparable values may be obtained by different observers in widely separated laboratories. The average amateur photographer can use the simple objective method described with equipment normally available. One set of charts consists of six high-contrast charts, printed in black ink on a white background, and the other set contains six low-contrast charts, printed in grey ink on a grey background. The range of the charts is $12-80$ lines $/ \mathrm{mm}$. in contrast with 3:5-56 lines $/ \mathrm{mm}$. of the charts in Circular 428 . Additional applications to the testing of goggle lenses for definition and prismatic power and of telescopes and binoculars for definition are also diseussed in Circular 533.

\section{Hydraulic Research in the United States}

INFORMATION compiled from various hydraulic and hydrologic laboratories, and from reports of research projects in private, State or Federal institutions in the United States and in five institutions in Canada, is contained in Miscellaneous Publication 208 of the National Bureau of Standards, entitled "Hydraulic Research in the United States" (pp. xii +204; edited by Helen K. Middleton and Sonya W. Matchett. Washington, D.C. : Government Printing Office, 1953 ; 1.25 dollars). The projects are numbered chronologically, and the number once assigned is repeated for identification purposes until the project is completed. 'Numbers above 1544 refer to projects reported for the first time; lower numbers to projects reported earlier in the previous editions (Misc. Publication 201, 1951 ; Misc. Publication 205, 1952). The information listed gives the title of the project; for whom conducted; the name of the person to whom correspondence should be addressed; the nature of the project (whether experimental, theoretical, etc.); and a brief description of the work, the results so far obtained and any published reports. There is also a comprehensive subject index. In the brief foreword by Dr. A. V. Astin, director of the National Bureau of Standards, Washington, 